\title{
Two Component Injection Moulding of Bi-material of Stainless Steel and Yttria Stabilized Zirconia - Green Part
}

\author{
(Pengacuanan Suntikan Dua Komponen of Bi-material of Stainless Steel and Yttria \\ Stabilized Zirconia - Green Part)
}

Ukwueze Bonaventure Emeka*, Abu Bakar Sulong, Norhamidi Muhamad, Zainuddin Sajuri \& Farrahshaida Salleh

\section{ABSTRACT}

\begin{abstract}
The two component injection molding (2C-PIM) is a promising technique for production of small, complex and high density, metal-ceramic parts in large scales. This method is a viable option for integrating incompatible functions or properties of the materials in a singular part or component. Thus, the production of near net shaped components via 2C-PIM is imperative due to cost effectiveness resulting from high unit volumes. In this study, the feasibility of joining stainless steel (17-4PH) and 3 mol\% yttria stabilized zirconia (3YSZ) materials in their green states was investigated. Two feedstock of SS17-4PH and $3 Y S Z$ powder materials was prepared based on optimum solid loading of 3 vol\% lower than value of the critical loading. The critical solid loading for the SS17-4PH and 3YSZ powder materials were 71vol\% and 53vol\% respectively, based on the oil absorption technique ASTM: D-281-12. The binder system utilized comprises of 60wt.\% palm stearin (PS) and 40wt.\% low density polyethylene (LDPE). The two materials were injected sequentially using the screw type injection molding machine (BOY 22A) to form a bi-material component. The green properties were investigated. The morphology of the individual green parts and composites depicted that the powders were optimally dispersed in the binder matrix indicating good mixture and compaction of the green components. The flexural strength of the single components of the bi-material was above $5 \mathrm{MPa}$. The strength of the bonding zone which was $1.4 \mathrm{MPa}$ indicates an evidence of bonding.
\end{abstract}

Keywords: Two component injection molding; Material characterization; Morphology; Density

\section{INTRODUCTION}

Powder injection moulding (PIM) is a manufacturing technique in producing metals and ceramic near net shapes (Liu et al. 2002). This technology produces the excellent results in the production of complex or intricate geometries with significant cost savings and large production capability which are not achievable with the conventional processes such as powder metallurgy (die compaction, isostatic pressing), deformation processes (forging, stamping) and casting processes (sand, die and investment casting). However, PIM applications have limitation to monolithic materials only such as stainless steel, titanium, alumina, cemented carbides, tungsten and other alloys (German et al. 2005). In this case, assembly of PIM product with another component is performed only after PIM fabrication.

Today, PIM process has evolved to 2C-PIM due to the growing demand for multi-functional components in modern applications. Thus 2C-PIM permits two classes of materials with incompatible functions or properties to be integrated in the green state into a singular component. The integration of different functions or properties in a singular component makes this process economically attractive. Just like in PIM process, 2C-PIM commences with preparation and rheological characterization of feedstock and subsequently injection moulding to produce a green component (Heaney 2012). The implementation process is usually based on injection of two different molten feedstocks either sequentially or simultaneously into the mould cavity. Consequently, the green component is then formed by interlocking of the two materials and ejected from the mould. Ceramic-metal joints have continued to be applied in a wide spectrum of engineering fields and industry as well as in microelectronic packaging and structural materials (Moya et al. 2007).

There have been notable demonstrations and successes of this technology such as the moulding process of stainless steel alumina with carbonyl iron system as core/shell (316L particulate alumina/carbonyl iron) (Alcock et al. 1998) and micro two-component moulding of $\mathrm{Al}_{2} \mathrm{O}_{3 /} \mathrm{T}_{\mathrm{i}} \mathrm{N}$ applied in manufacturing of $\mathrm{U}$-shaped heater (Piotter et al. 2007). Baumann et al. (2009) also fabricated 3Y-TZP/stainless steel composite structure using co-powder injection. Two component micro-injection moulding of stainless steel $(316 \mathrm{~L} / 17-4 \mathrm{PH})$ and $(316 \mathrm{~L} / \mathrm{Fe})$ powders for producing magnetic-nonmagnetic bimetals have also been investigated (Imgrund et al. 2008). The European specific targeted research project (STREP) have developed many ceramic components for automotive and railway applications using two-component ceramic injection moulding (2C-CIM) (Moritz $\&$ Mannschatz 2010). However, large scale adoption of this technology is yet to be realized due to limitations imposed by differences in properties of material systems involved.

There are also challenges relating to the inherent powder characteristics such as porosity or contamination which affect structural properties of a joint and performance or integrity. The powder characteristics which include particle 
shape, size and surface area influence porosity which consequently affect the physical properties of the preform. The problem is how to obtain a sound bonding between the dissimilar materials. Though some impressive results have been recorded, successful implementation of this technology remains summarily an ambitious challenge. Thus 2C-PIM process has continued to be a subject of intensive research. However, investigations reveal that direct joining of zirconia to metals is feasible if appropriate processing condition is employed (Dourandish et al. 2011).

The concept of 2C-PIM is based on joining of the ceramic- metal composite in their green states and subsequently, obtaining the desired density through further processing which includes de-binding and sintering. So far, various processing techniques utilizing interlayer material for joining have been established (Jadoon et al. 2004; Singh et al. 2008). In these techniques, the disadvantage of inclusion of a third material different from the base materials and additional manufacturing step are usually imposed (Dourandish et al. 2008). Thus, direct joining of composites such as through $2 \mathrm{C}$-PIM process ensures reduction in the process chain and complexity in addition to assembly cost savings.

The materials chosen for this investigation are stainless steel (17-4PH) and yttria stabilized zirconia (3YSZ). SS17$4 \mathrm{PH}$ is an attractive choice in many applications because of its properties such as excellent corrosion resistance, high fatigue and good mechanical strength. Thus SS17-4PH are widely employed for many applications in the aerospace, chemical, petrochemical and food processing industries (Schade et al. 2006). On the other hand, zirconia has a broad spectrum of applications in the industry due to good combinations of wear resistance, flexural strength and fracture toughness as well as high temperature stability, biocompatibility and optimal dielectric constant (Betz et al. 2000). Thus, the unique and versatile properties of zirconia make this material attractive to be joined to metals. Hence, the demand for reliable bonds between zirconia and metals have continued to increase (Mei et al. 2001). Applications requiring zirconia-metal joining can therefore be found in many diverse fields such as heterogeneous catalysis, microelectronics and optoelectronics including in fuel cells, structural composites, coating of nuclear reactors as well as surgical implants (Munoz et al. 2006).

The purpose of this research is therefore to investigate the feasibility of processing green bi-material (SS 17-4PH/3YSZ) from the selected PIM materials through 2C-PIM process.

\section{METHODOLOGY}

The SSI7-4PH and 3YSZ powders have average sizes as $22 \mu \mathrm{m}$ and $<5 \mu \mathrm{m}$ according to manufacturer's index. The former was supplied by Sandvick Technologies Ltd while the later was purchased from Nabond Technologies Co Ltd. Their densities determined using Helium pycnometer were 7.78 $\mathrm{g} / \mathrm{cm}^{3}$ and $5.96 \mathrm{~g} / \mathrm{cm}^{3}$ for SS17-4PH and 3YSZ respectively. The chemical compositions of the SS17-4PH powder as provided by the manufacturer are shown in Table 1. The XRD analysis of both powders scanned using a diffractometer (XRD D8 ADVANCE Germany) over the range of 2-theta from $0^{\circ}$ to $80^{\circ}$ are depicted in Figure 1. The critical powder volume concentration (CPVC) or critical solid loading for both powders SS17-4PH and $3 \mathrm{YSZ}$ were determined as $71 \mathrm{vol} \%$ and $53 \mathrm{vol} \%$ respectively using the oil absorption technique ASTM; D-28112. These values correspond to the maximum torque beyond which the mixing torque begins to fall. Each of the feedstock was prepared based on optimal value of $3 \mathrm{vol} \%$ lower than the critical value. The binder system selected for this investigation was $60 \%$ palm stearin (PS) as a primary binder and $40 \%$ low density polyethylene (LDPE) as a secondary or backbone binder. The characteristics of the binders were investigated using the differential scanning calorimeter (DSC) and thermo-gravimeteric analyzer (TGA). While the DSC defines the melting point of the binders, the TGA provides the decomposition temperature of the binders. The characterization has been reported elsewhere (Ukwueze et al.2016). Mixing of feedstock was achieved using brabender mixer at a temperature of $140^{\circ} \mathrm{C}$ and speed of 30 rpm. Feedstock homogeneity was attained when the torque became constant for more than 30 minutes. The schmidaz CFT-500D capillary rheometer was utilized to investigate the deformation behavior under varied temperatures. The rheological investigations revealed pseudo-plastic and shear thinning behavior suitable for injection moulding (Ukwueze et al. 2016). The different classes of feedstock were processed in sequence to form a bimaterial using the barrel type injection moulding machine (Boy 22A). The density of single and composite green parts was determined using Mettler Toledo MS204S based on Archimedes water immersion method. The surface morphology of green parts of 3YSZ, 17-4PH and bimaterial of $3 \mathrm{YSZ} / \mathrm{SS} 17-4 \mathrm{PH}$ were observed using scanning electron microscopy (SEM). The flexural strength of the individual green parts and bonding strength of the bi-material SS-4PH /3YSZ were determined using Instron universal test machine (INSTRON 5567) based on MPIF standard 4.

\section{RESULTS AND DISCUSSION}

\section{MATERIAL CHARACTERIZATION}

The obtained XRD analysis result for 3 YSZ powder indicates a two phase structure viz; Baddeleylite (monoclinic) and zirconium yttrium oxide (tetragonal). This corresponds to the

TABLE 1. Chemical composition of SS17-4PH powder according to the manufacturer

\begin{tabular}{lccccccccccc}
\hline Elements & $\mathrm{Cr}$ & $\mathrm{Ni}$ & $\mathrm{Cu}$ & $\mathrm{Mn}$ & $\mathrm{Si}$ & $\mathrm{Nb}$ & $\mathrm{C}$ & $\mathrm{Mo}$ & $\mathrm{N}$ & $\mathrm{P}$ & $\mathrm{S}$ \\
\hline$\%$ Composition & $16-17$ & $4-5$ & $3.5-4.5$ & 1 & 1 & $0.15-0.45$ & 0.01 & 0.3 & 0.2 & 0.035 & 0.03 \\
\hline
\end{tabular}




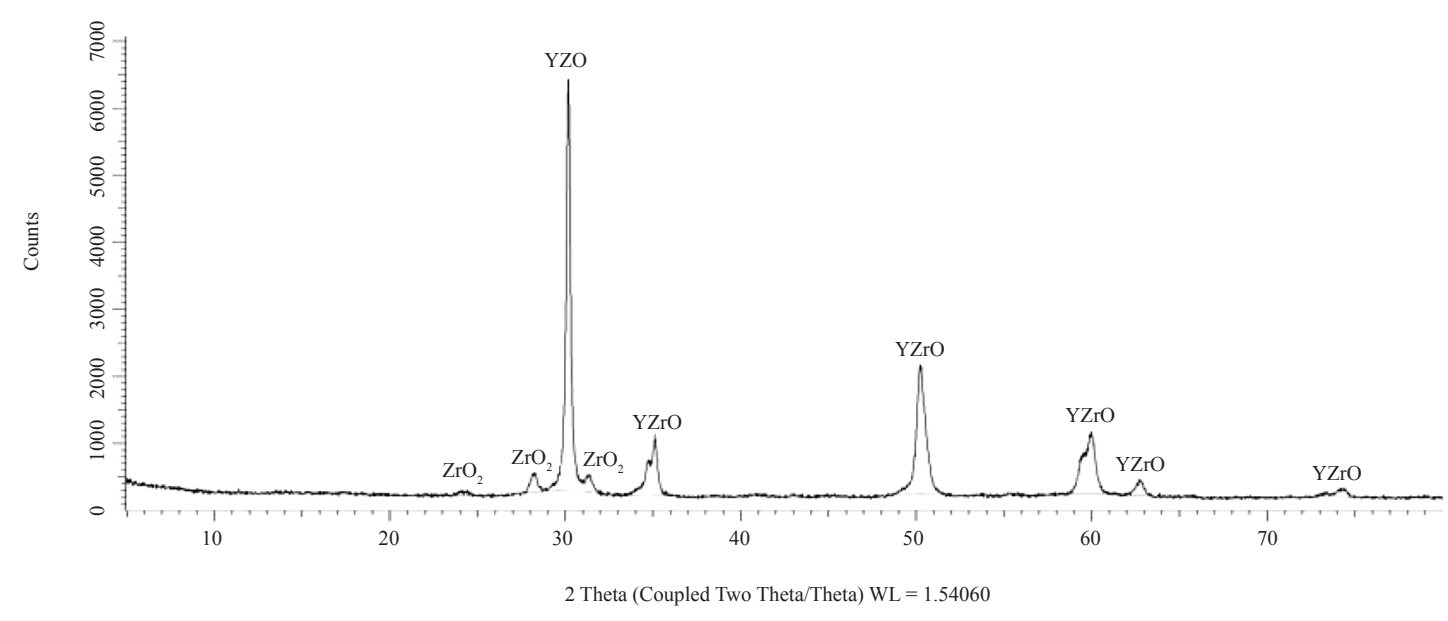

FIGURE 1(a). XRD analysis of 3YSZ powder material

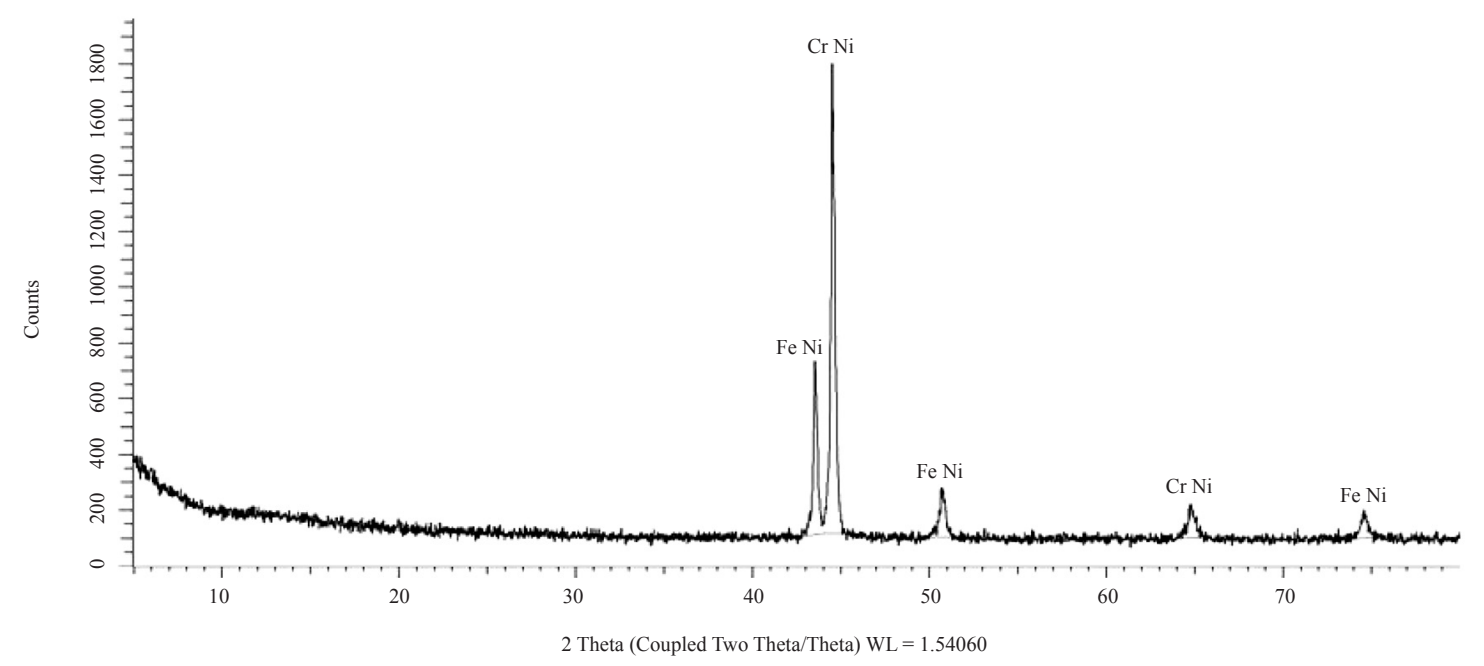

FIGURE 1(b). XRD Analyiss of SS17-4PH powder.

tetragonal phase with minor presence of monoclinic which appear as little isles in the matrix which may contribute to higher fracture toughness (Sun et al. 1999).

Zirconia $\left(\mathrm{ZrO}_{2}\right)$ is a white crystalline oxide of zirconium which exists in a natural form as baddeleyite. It is difficult to produce ceramic part with pure zirconia because of phase transformations due to allotropic changes during heating and cooling. The equation (1) represents the phase transformation of zirconia in relation to temperature changes (Rajabi et al. 2015).

$$
\mathrm{ZrO}_{2}-\mathrm{t}-\mathrm{ZrO}_{2}{ }_{950^{\circ} \mathrm{C}}{ }^{1170^{\circ} \mathrm{C}} \rightarrow \mathrm{c}-\mathrm{ZrO}_{2} \rightarrow \text { Liquid }
$$

The metastability of tetragonal or cubic form can be maintained at room temperature by alloying zirconia with other cubic oxides thus preventing the catstrophic failure when using pure zirconia (Lughi \& Sergo 2010). These oxides are known as stabilizers such as $\mathrm{CaO}, \mathrm{MgO}$ and $\mathrm{Y}_{2} \mathrm{O}_{3}$.
Thus yttrium stabilized zirconia (YSZ), allows metastable tetragonal and cubic phases to be stable at lower temperatures with enhanced mechanical, thermal and electrical properties (Herrera et al. 2013).

Table 1 depicts the chemical composition of the stainless steel 17-4PH according to manufacturer's specification while Figure 1(b) indicates the obtained results from XRD analysis. The main elements include; $\mathrm{Fe}, \mathrm{Cr}$ and Ni. SS17-4PH is a martensitic precipitation hardening steel. The high strength in the steel is derived from addition of such elements as copper and niobium which form intermetallic precipitates during age treatment. These precipitates formed hinder movement of dislocation and hardens the alloy.

This material is known to exhibit considerably higher strength compared to more commonly available austenitic stainless steels 316L. Precipitation hardening steels also exhibit improved corrosion resistance comparable to austenitic alloys which may be explained by high chromium content (up to $17 \%$ ) in addition to a few percentage of nickel. 


\section{CO-INJECTION MOULDING}

Molding is a critical stage that replicates the shape of the mould cavity on the PIM material. Many associated problems at this stage arise due to powder-binder incompatibility (Ismail et al. 2008). It is therefore important that the optimal binder content is precisely estimated based on the powder characteristics to ensure that binder envelopes the powder particle completely by a thin film. The amount of binder is related to particle packing. Thus, moulding must be performed at a solid content with slightly more binder than that corresponding to the critical solid loading (German \& Bose 1997). Excessive binder causes powder-binder separation and in-homogeneities in moulded parts while insufficient binder leads to voids or trapped air pockets which result to high viscosity moulding.

The moulding parameters are heavily interactive at any particular moulding condition, thus the solution to one problem can lead to a defect in another form. The critical parameters include; injection temperature, mould temperature, injection speed, injection pressure and cooling time. The injection temperature must typically be set above the melting point of the higher molecular binder or backbone binder. This temperature influences the viscosity of the melt and consequently the ability to fill the mould cavity. Too low temperature setting can result in flow lines evident on the part due to poor flow characteristics (Heaney et al. 2003). On the other hand, higher temperatures can cause blister effects. The mould temperature must also be set at a temperature below the melting point and recrystallization temperature of the lower molecular weight binder component or primary binder. The mould temperature affects the development of stresses, rate of cooling and filling of the mould cavity. Too low mould temperature can lead to incomplete filling of the part or other defects while higher mould temperatures can lead to blisters and flashing (Heaney et al. 2003). The injection speed is important to ensure the die cavity promptly fills in a short time while injection pressure drives the filling of the mould. Adequate cooling time is also essential for redistribution of internal stresses and consequently, satisfactory part.

In this investigation, the barrel type injection moulding (BOY 22A) was manipulated to process the green composite. In one sequence, one class of the feedstock material was fed to produce a semi-finished part. The semi-finished part was replaced in the mould and the second class of feedstock material was fed to complete the part in another sequence. Good bonding of SS17-4PH with 3YSZ in the green state was obtained and no flaw was observed. However, a standard equipment for sequential moulding utilizes two injection units for injection of two different feedstocks into the required shape (Heaney et al. 2003). Following the molding of one part in the cavity, the tooling is rotated to open up another cavity for molding of the remaining part which interlocks the previous part. It has been reported that a very narrow interface is usually obtained when sequential moulding approach is employed compared to simultaneous moulding method (Imgrund et al. 2007). This is understandable due to existence of temperature gradient between the two parts since one part cools down before the second part is injected.

The molding parameters used for this investigation were based on the manufacturer's specifications according to feedstock materials. Table 2 shows the important molding parameters used in this study. Meanwhile, Figure 2 shows the individual green components of SS17-4PH, $3 \mathrm{YSZ}$ and the green bi-material of SS17-4PH/3YSZ.

TABLE 2. Parameters used for co-injection moulding

\begin{tabular}{ccccccccc}
\hline Injection & Mould & Nozzle & Injection & \multicolumn{2}{c}{ Stroke } & \multicolumn{3}{c}{ Barrel Temperature } \\
Press. (bar) & Temp. (T6) & Temp. (T5) & Speed $\left(\mathrm{cms}^{-1}\right)$ & $(\mathrm{mm})$ & T1 & T2 & T3 & T4 \\
\hline 100 & 30 & 182 & 100 & 24 & 145 & 165 & 165 & 175 \\
\hline
\end{tabular}
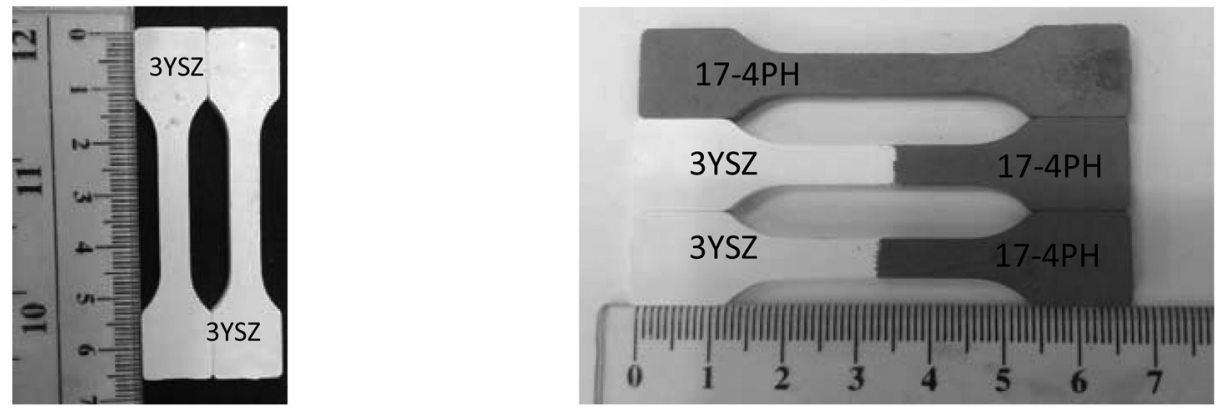

FIGURE 2. Individual components and bi-materials of SS17-4PH and 3YSZ materials 
MORPHOLOGY OF CO-INJECTED PARTS

Figure 3 shows the SEM micrograph of the single green components of SS17-4PH, $3 \mathrm{YSZ}$ and the green bi-material structure of SS17-4PH/3YSZ. The micrographs show

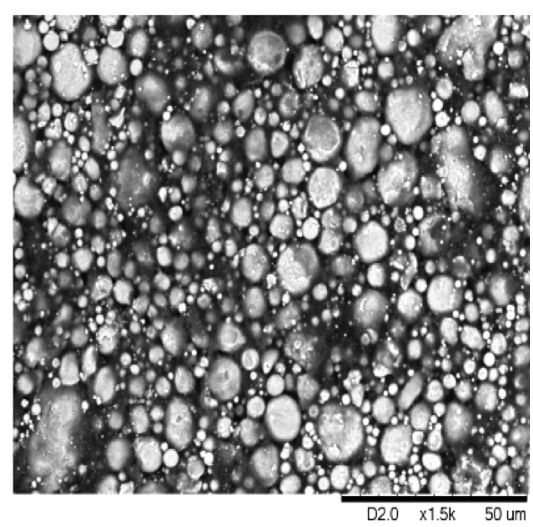

FIGURE 3(a). Micrograph of SS17-4PH evidence of well dispersed powder particles in the binder matrix indicating good mixture and compaction of the part. For the green bi-material part, the interface zone indicates a wavy partition while the regions far from it represent the micrograph of the individual components.

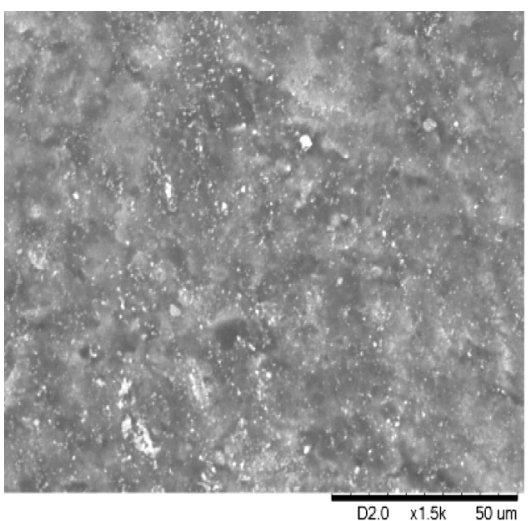

FIGURE 3(b). Micrograph of 3YSZ

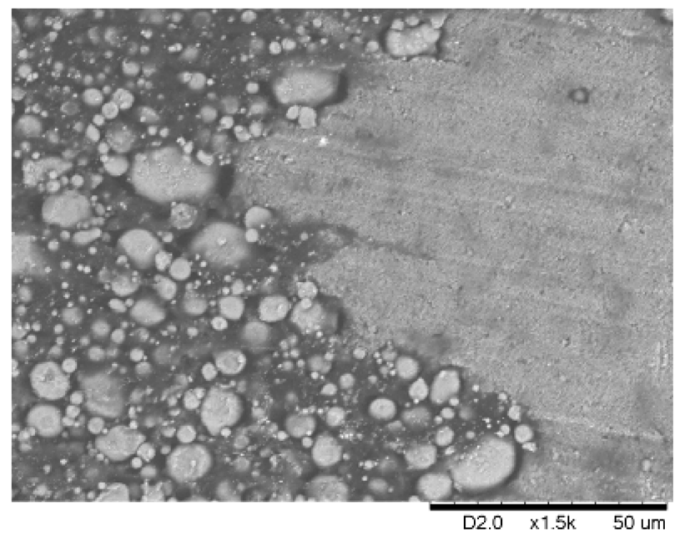

FIGURE 3(c). Micrograph of bi-material SS17-4PH/3YSZ interface

DENSITY OF GREEN PARTS

Table 3 shows the result of densities using Archimedes method for the single components of SS17-4PH, 3YSZ and the bi-material structure of SS17-4PH/3YSZ. The density of the bi-material indicates intermediate value between the values of density of the individual components although this does not correspond to the average sum of the values. This may be attributed to increased density due to interpenetration of the materials at the joint interface during moulding process. The theoretical densities approximate the experimental values indicating good mixture of the component materials.

TABLE 3. Measured and theoretical densities of the green parts and bi-materials

\begin{tabular}{lccc}
\hline Materials & 3YSZ & SS-4PH & 3YSZ/ SS-4PH \\
\hline Measured density $\left(\mathrm{g} / \mathrm{cm}^{2}\right)$ & 3.3 & 5.56 & 4.50 \\
Theoretical density $\left(\mathrm{g} / \mathrm{cm}^{2}\right)$ & 3.3 & 5.58 & \\
\hline
\end{tabular}

MECHANICAL TESTING OF THE GREEN PARTS

To evaluate adequacy of stiffness and mechanical strength of the green components, some samples were subjected to triple bending tests. The three-point bending was conducted in line with MPIF standard 41. Each specimen of the single components of SS17-4PH and $3 \mathrm{YSZ}$ was supported transversely to the load over a span of $24 \mathrm{~mm}$ and the mid span was loaded gradually until fracture of the specimen. A cross head velocity of $0.5 \mathrm{~mm} / \mathrm{min}$ was utilized. The width and thickness of the samples were $5.44 \mathrm{~mm}$ and $2.95 \mathrm{~mm}$ respectively. The obtained flexural stress at maximum load were $6.60 \mathrm{MPa}$ at $0.6 \%$ strain and $7.90 \mathrm{MPa}$ at $1.7 \%$ strain for SS17-4PH and 3YSZ green parts respectively. The flexural strength of both is above $5 \mathrm{MPa}$ which according to German and Bose (1997) is allowable for mechanical strength of injection moulded articles. The green bi-materials (SS174PH/3YSZ) were supported at both ends and loaded in tension over a span of $16.50 \mathrm{~mm}$ until fracture for evaluation of the bonding strength (joint). The strength of $1.4 \mathrm{MPa}$ at $0.8 \%$ 
strain indicates evidence of bonding of SS17-4PH material to 3 YSZ. The speed used for this loading is $0.1 \mathrm{~mm} / \mathrm{min}$.

\section{CONCLUSIONS}

The processing of single and bimaterial green components of SS17-4PH and 3YSZ have been investigated. The components were defect free. SEM evaluations of the components revealed good mixing and compaction of the materials. While flexural strength of above $5 \mathrm{MPa}$ for the single materials indicates good mechanical properties suitable for next processing steps such as de-binding and sintering, the strength of $1.4 \mathrm{MPa}$ is only an indication of joining. It can be stated that while other material processing methods may favour processing of large parts at economic cost, this method allows time and cost effective production of small, complex and net shape metal-ceramic components in large numbers. Although this technology is a relatively new technique with potentials yet to be fully realized, some gains have been recorded in the production of multifunctional component.

\section{ACKNOWLEDGEMENT}

The authors would like to thank the Ministry of Higher Education Malaysia and Universiti Kebangsaan Malaysia for their financial support under the grant TRGS/2/2014/ $\mathrm{UKM} / 02 / 4 / 1$ and DIP/2016/009.

\section{REFERENCES}

Alcock, J., Logan, P. \& Stephenson, D. 1998. Surface engineering by co-injection moulding. Surface and Coatings Technology 105(1): 65-71.

Baumann, A., Moritz, T. \& Lenk, R. 2009. Multi component powder injection moulding of metal-ceramic composites. Euro PM2009 2: 55-58.

Betz, U., Sturm, A., Löffler, J., Wagner, W., Wiedenmann, A. \& Hahn, H. 2000. Microstructural development during final-stage sintering of nanostructured zirconia based ceramics. Materials Science and Engineering: A 281(1): 68-74.

Dourandish, M., Simchi, A., Hokamoto, K. \& Tanaka, S. 2011. Phase formation during sintering of nanocrystalline zirconia/stainless steel functionally graded composite layers. Materials Letters 65(3): 523-526.

Dourandish, M., Simchi, A., Tamjid Shabestary, E. \& Hartwig, T. 2008. Pressureless sintering of 3Y-TZP/ stainless-steel composite layers. Journal of the American Ceramic Society 91(11): 3493-3503.

German, R. M. \& Bose, A. 1997. Injection Molding of Metals and Ceramics. Metal Powder Industries Federation.

German, R. M., Heaney, D. F. \& Johnson, J. L. 2005. Bimaterial components using powder injection molding: densification, shape complexity and performance attributes. Advances in Powder Metallurgy and Particulate Materials 1: 41-52.
Heaney, D. 2012. Powders for metal injection moulding. Handbook of Metal Injection Molding, Woodhead Publishing Limited Cambirdge, pp. 50-63.

Heaney, D., Suri, P. \& German, R. 2003. Defect-free sintering of two material powder injection molded components Part I Experimental investigations. Journal of Materials Science 38(24): 4869-4874.

Herrera, A. M., Martins de Oliveira, A. A., Novaes de Oliveira, A. P. \& Hotza, D. 2013. Processing and characterization of yttria-stabilized zirconia foams for high-temperature applications. Journal of Ceramics, 2: 3-11.

Imgrund, P., Rota, A. \& Simchi, A. 2008. Microinjection moulding of $316 \mathrm{~L} / 17-4 \mathrm{PH}$ and $316 \mathrm{~L} / \mathrm{Fe}$ powders for fabrication of magnetic-nonmagnetic bimetals. Journal of Materials Processing Technology 200(1): 259-264.

Imgrund, P., Rota, A. \& Wiegmann, M. 2007. Getting better bonding at tiny interfaces. Metal Powder Report 62(3): 31-34.

Ismail, M. H., Muhamad, N. \& Omar, M. A. 2008. Characterization of Metal Injection Molding (MIM) feedstock based on water soluble binder system. Jurnal Kejuruteraan 20: 11-18.

Jadoon, A., Ralph, B. \& Hornsby, P. 2004. Metal to ceramic joining via a metallic interlayer bonding technique. Journal of Materials Processing Technology 152(3): 257-265.

Liu, Z., Loh, N., Tor, S., Khor, K., Murakoshi, Y., Maeda, R. \& Shimizu, T. 2002. Micro-powder injection molding. Journal of Materials Processing Technology 127(2): 165-168.

Lughi, V. \& Sergo, V. 2010. Low temperature degradationaging-of zirconia: A critical review of the relevant aspects in dentistry. Dental Materials 26(8): 807-820.

Mei, J. \& Xiao, P. 1999. Joining metals to zirconia for high temperature applications. Scripta Materialia 40(5): 587-594.

Moritz, T. \& Mannschatz, A. 2010. 2C ceramics moves into the industrial reality zone. Metal Powder Report 65(3): 22-25.

Moya, J. S., Lopez-Esteban, S. \& Pecharromán, C. 2007. The challenge of ceramic/metal microcomposites and nanocomposites. Progress in Materials Science 52(7): 1017-1090.

Munoz, M., Gallego, S., Beltrán, J. \& Cerdá, J. 2006. Adhesion at metal-ZrO 2 interfaces. Surface Science Reports 61(7): 303-344.

Piotter, V., Finnah, G., Zeep, B., Ruprecht, R. \& Haußelt, J. 2007. Metal and ceramic micro components made by powder injection molding. Materials Science Forum 32: 45-53.

Rajabi, J., Sulong, A. B., Muhamad, N. \& Raza, M. 2015. Powder compaction of bimaterials: stainless steel 316L and nanocrystalline yttria stabilised zirconia. Materials Technology 30(5): 313-320.

Schade, C., Stears, P., Lawley, A. \& Doherty, R. 2006. Precipitation Hardening PM Stainless Steels. Advances 
in Powder Metallurgy and Particulate Materials 1: 7-11.

Sciti, D., Bellosi, A. \& Esposito, L. 2001. Bonding of zirconia to super alloy with the active brazing technique. Journal of the European Ceramic Society 21(1): 45-52.

Singh, M., Shpargel, T. P. \& Asthana, R. 2008. Brazing of yttria-stabilized zirconia (YSZ) to stainless steel using $\mathrm{Cu}, \mathrm{Ag}$, and Ti-based brazes. Journal of Materials Science 43(1): 23-32.

Sun, J., Gao, L. \& Guo, J. 1999. Influence of the Initial pH on the adsorption behaviour of dispersant on nano zirconia powder. Journal of the European Ceramic Society 19(9): 1725-1730.

Ukwueze, B. E., Sulong, A. B. \& Muhamad, N. 2016. Rheological investigation of powder injection moulding materials using polyethylene with palm strearin binder system. ASPIM 2016, Proceeding.

*Ukwueze Bonaventure Emeka

Department of Mechanical and Production Engineering Institute of Management and Technology, P.M.B.01079 Enugu, Nigeria.
Abu Bakar Sulong, Norhamidi Muhamad, Zainuddin Sajuri Department of Mechanical \& Materials Engineering Faculty of Engineering \& Built Environment Universiti Kebangsaan Malaysia, Malaysia.

Farrashaida Mohd Salleh Faculty of Mechanical Engineering Universiti Teknologi Mara (UiTM) 40450 Shah Alam, Malaysia.

*Corresponding author; email: ukwbonaem@gmail.com

Received date : $2^{\text {nd }}$ May 2017

Accepted date : $14^{\text {th }}$ September 2017

In Press date : $16^{\text {th }}$ October 2017

Published date : $30^{\text {th }}$ October 2017 
